stools. In this method, any bacterial DNA present in stools is amplified by polymerase chain reaction (PCR) through a process that introduces fluorescent groups in the amplicons. The labeled amplicons are then hybridized with a DNA microarray that contains pathogenspecific probes. The pathogens are ultimately identified by measuring the fluorescence of microarray-hybridized amplicons. The PCR primers used in the study did not amplify DNA of human, viral, or fungal origin, and the limit of detection for the approach was $\sim 10^{3}$ colonyforming units per milliliters for one species or bacterial pathogen. When 1,500 samples of clinical, diarrheal stool and 200 of healthy stool were tested, the microarray approach had $100 \%$ sensitivity and $95.2 \%$ specificity, as measured against routine culture. Specifically, DNA microarray correctly identified the pathogens present in 458 samples, and it identified pathogens in 51 samples that were designated as pathogen-free via bacterial culture.

As Mao et al.'s method proved to be as sensitive as conventional bacterial culture, and can be implemented in about $5 \mathrm{~h}$, the authors conclude that their approach can potentially complement or replace established clinical tests.

Original article Mao Z et al. (2008) DNA microarray for direct identification of bacterial pathogens in human stool samples. Digestion 78: 131-138

\section{Administration of physiologic plasma lipid reduces food intake in rats and mice}

Regulation of the intake of dietary fat, the macronutrient that most promotes obesity, is a primary target of research into obesity. Gillum et al. found that fasted rats fed a high-fat diet display significantly increased plasma concentrations of $\mathrm{N}$-acylphosphatidylethanolamines (NAPEs), and that intraduodenal infusion of a lipid-but not of dextrin or casein-induced a significant increase in lymph concentrations of NAPEs.

Intraperitoneal injection of the most abundant NAPE, C16:0, caused a dose-dependent decrease in food intake in mice. In rats, intraperitoneal infusion of $100 \mathrm{mg} / \mathrm{kg}$ of $\mathrm{C} 16: 0$ NAPE led to a significant reduction of food intake, but did not cause conditioned taste aversion. Importantly, the $7 \mathrm{~h}$ profiles of the total plasma concentration of NAPEs in rats were similar following intraduodenal lipid infusion or injection of $100 \mathrm{mg} / \mathrm{kg} \mathrm{C16:0} \mathrm{NAPE.}$ Data suggest that the appetite-reducing effect of C16:0 NAPEs is mediated by targets in the central nervous system: both intravenously administered, radiolabeled C16:0 NAPE, which became concentrated in the hypothalamus, and intracerebroventricular infusion of C16:0 NAPE (at far lower doses than those used in intraperitoneal injection) led to significant reductions in food intake.

Although postprandial increases in plasma concentration of NAPEs stopped in rats that were fed a high-fat diet for 35 days, exogenous administration of C16:0 NAPE still suppressed their food intake. By contrast, the appetitereducing properties of leptin are quickly diminished by obesity. This property suggests that NAPEs should be investigated as physiologic therapeutics.

Original article Gillum MP et al. (2008)

$\mathrm{N}$-acylphosphatidylethanolamine, a gut- derived circulating factor induced by fat ingestion, inhibits food intake. Cell 135: 813-824 